\title{
SAEInternational
}

\section{Evaluation of Transient Refrigerant Migration Modeling Approach on Automotive Air Conditioning Systems}

Bin $\mathrm{Li}$

Univ. of Illinois at Urbana-Champaign

Steffen Peuker

Univ. of Alaska Anchorage

Pega Hrnjak and Andrew Alleyne

Univ. of Illinois at Urbana-Champaign

\begin{abstract}
Automotive air conditioning systems are subject to constantly changing operation conditions and steady state simulations are not sufficient to describe the actual performance. The refrigerant mass migration during transient events such as clutch-cycling or start-up has a direct impact on the transient performance. It is therefore necessary to develop simulation tools which can accurately predict the migration of the refrigerant mass. To this end a dynamic model of an automotive air conditioning system is presented in this paper using a switched modeling framework. Model validation against experimental results demonstrates that the developed modeling approach is able to describe the transient behaviors of the system, and also predict the refrigerant mass migration among system components during compressor shut-down and start-up (stop-start) cycling operations. To further investigate the potential of the dynamic modeling tools, two simulation examples of evaluating the system performance are given in the paper: (i) impact of system component variations on the refrigerant mass migration; and (ii) control implementation for the system start-up performance improvement.
\end{abstract}

\section{INTRODUCTION}

Automotive air conditioning systems in actual vehicles are subject to constantly changing operation conditions, many start-ups over their lifetime and, for clutch cycling systems, repetitive stop-start operations of the compressor. To evaluate the performance of air conditioning systems under these transient conditions requires expensive experimental measurements. Computer simulations can reduce the time and expenses required for experimentation but need to represent the dynamics of the real system.

The correct prediction of the refrigerant mass migration during the dynamic operations is paramount, since refrigerant mass migration affects the transient performance of air conditioning systems [1]. The redistribution of refrigerant mass either at start-up or during clutch cycling results in energy losses. Both, Wand and Wu [2] and Peuker and Hrnjak [3], provide experimental data demonstrating that compressor energy, and hence energy losses, can be reduced by preventing refrigerant mass migration during the compressor shut-down period. Both investigations show the importance of predicting the movement of refrigerant mass accurately. Therefore, dynamic simulations matching only pressure and temperature developments are not sufficient to faithfully represent real systems.

Peuker and Hrnjak [4] present experimentally measured data of pressure, temperature and the migration of refrigerant mass for an automotive fixed orifice tube system during the compressor stop-start operation. Their data provides a baseline to validate the capability of dynamic simulations to predict the refrigerant mass migration. A dynamic model of 
the automotive air conditioning system used by Peuker and Hmjak [4] has been developed using the modeling framework of Li and Alleyne [].

In this paper, the dynamic model of the automotive air conditioning system is described and model validation against experimental data from [4] demonstrates the validity of the developed model in capturing the refrigerant mass migration during the stop-start operation. Simulation examples are presented to show the potential benefits of the dynamic modeling tools in representing the real vehicle system dynamics. Finally, a conclusion section summarizes the main points of the paper.

\section{EXPERIMENTAL SYSTEM}

The experimental system used for transient modeling and validation is an R134a automotive air conditioning system consisting of the following components: compressor, condenser, fixed orifice tube, evaporator, and accumulator. The components are installed into the experimental facility [4] with the same difference in vertical height as in the vehicle. The schematic of the experimental system is shown in Figure 1. As seen in Figure 1 ball valves are installed on either side of each component and, by closing these ball valves simultaneously, the refrigerant mass can be trapped in each section. The published experimental data in [4] are used for the validation of the dynamic model presented in this paper. The reader is referred to Appendix for brief descriptions of the experimental system components, and detailed specifications are provided in [6]. The accuracy and repeatability of the refrigerant mass measurement are verified by Peuker [6], and more information about the experimental system set-up, the refrigerant mass measurement method, experimental results and analysis can be found in [4]][] $]$.

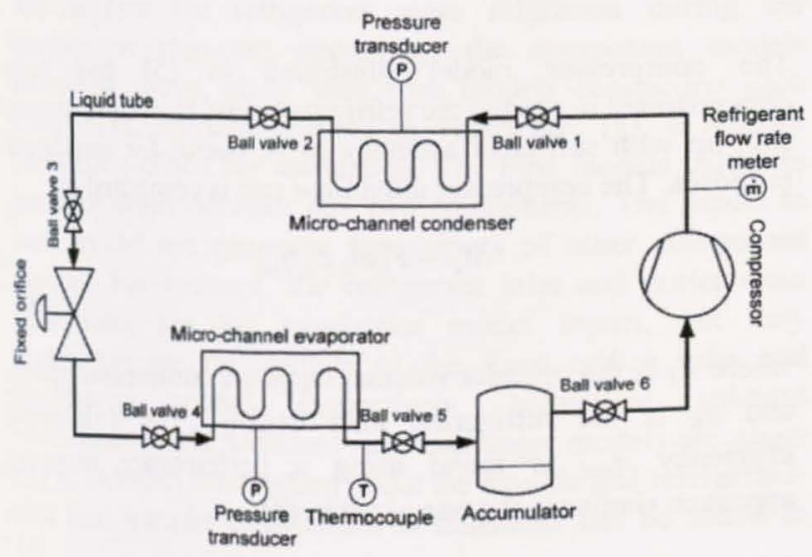

Figure 1. Schematic of the experimental system.

\section{SYSTEM MODELING}

This section is divided into three parts. Using the switched modeling framework from [5], the component models are introduced first for simulating the stop-start transients of the automotive air conditioning system. Second, methods to calculate the refrigerant mass in each component are presented, and the third part illustrates the simulation environment.

\section{COMPONENT MODELING}

The automotive air conditioning system as shown in Figure 1 is subdivided into four components, each of which is discussed below.

\section{Heat exchangers}

Most of the attention in the system modeling is paid to the heat exchangers, both condenser and evaporator. Since the compressor stop-start operations produce very large transients, a switched moving-boundary modeling framework is developed and presented in [5] to describe the refrigerant transient responses. In particular, the heat exchangers are developed to accommodate different model representations. The dynamic state vectors in Equations (1) and (2) represent the condenser and evaporator conditions at each instant in time. The pseudo-state technique [7] is applied to maintain the uniform state vector, independent of model representations. The state derivative equation is formulated in a nonlinear descriptor form given in Equation (3), and each model representation has its own coefficient matrix $Z(\hat{x}, \vec{u})$ and forcing function $f(\bar{x}, \bar{u})$ for storing thermodynamic variables, and mass and energy balance terms. An advantage of this approach is the tracking of the vapor and liquid refrigerant dynamic states in numerical simulations while ensuring refrigerant mass conservation during switches in system model representations.

$$
\begin{gathered}
\vec{x}_{c}=\left[\begin{array}{lllllllll}
h_{c 1} & P_{c} & h_{c 3} & \zeta_{c 1} & \zeta_{c 2} & T_{c 1, w} & T_{c 2, w} & T_{c 3, w} & \bar{\gamma}_{c}
\end{array}\right]^{T} \\
\vec{x}_{e}=\left[\begin{array}{llllll}
\zeta_{e 1} & P_{e} & h_{e 2} & T_{e 1, w} & T_{e 2, w} & \bar{\gamma}_{e}
\end{array}\right]^{T} \\
Z(\bar{x}, \vec{u}) \cdot \dot{\bar{x}}=f(\bar{x}, \bar{u})
\end{gathered}
$$

Based on the switched modeling method and experimental study [4], the condenser is developed to consist of four different model representations in Figure 2, and two different model representations, as shown in Figure 3, are used for the evaporator. The dynamic states in Equations (1) and (2) are applied to describe the heat exchanger transients, where the mean void fraction $\bar{\gamma}_{c}$ and $\bar{\gamma}_{e}$ are used for switching purposes 
[7]. The reader is referred to [5][7] for detailed descriptions about the derivations of air-side and refrigerant-side governing equations in the different model representations for the heat exchangers, as well as switching schemes to simulate the stop-start dynamics.

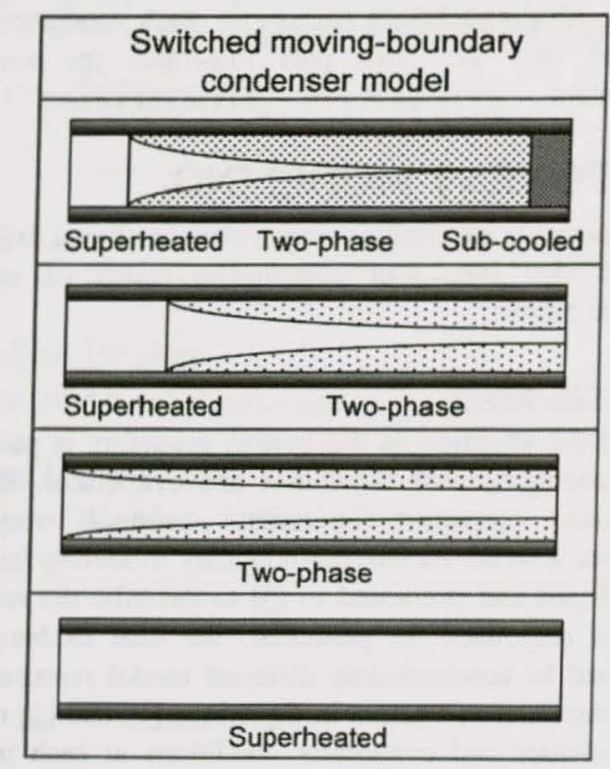

Figure 2. Condenser model structure.

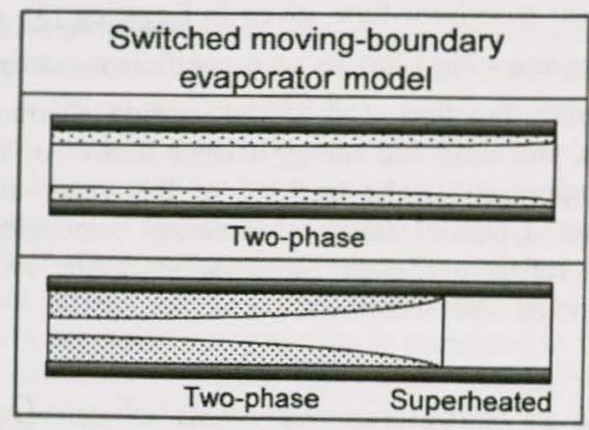

Figure 3. Evaporator model structure.

\section{Accumulator}

The accumulator is a key component in the automotive air conditioning system. Its primary function is to store excess refrigerant mass to ensure system capacity over a large range of operating conditions. Meanwhile, it captures two-phase refrigerant thus preventing damage to the compressor. Two dynamic states, refrigerant pressure $P_{a c}$, and refrigerant enthalpy $h_{a c}$, are defined to describe the refrigerant dynamics inside the accumulator. By applying mass and energy conservation principles, the governing equations are given below.

$$
\frac{\delta \rho_{a c}}{\delta P_{a c}} \frac{d P_{a c}}{d t}+\frac{\delta \rho_{a c}}{\delta h_{a c}} \frac{d h_{a c}}{d t}=\frac{\dot{m}_{i, a c}-\dot{m}_{o, a c}}{V_{a c}}
$$

$$
-\frac{1}{\rho_{\alpha \alpha}} \frac{d P_{\alpha c}}{d t}+\frac{d h_{\alpha c}}{d t}=\frac{(U A)_{\alpha x}\left(T_{\alpha a b b}-T_{\alpha \alpha}\right)+\dot{m}_{i, \alpha \alpha}\left(h_{i, \alpha}-h_{\alpha}\right)+\dot{m}_{\alpha, \alpha}\left(h_{i \alpha}-h_{\alpha}\right)}{\rho_{\alpha \alpha} V_{\alpha}}
$$

where the term $(U A)_{a c}\left(T_{a m b}-T_{a c}\right)$ represents the heat transfer rate from the ambient air to the refrigerant inside the accumulator. The heat transfer is considered since it influences the refrigerant mass migration of the accumulator.

\section{Fixed orifice tube and compressor}

Since the dynamics of the mass flow devices (fixed orifice tube and compressor) are generally an order of magnitude faster than those of the heat exchangers [8], these two components are considered to be static models. The mass flow rate across the fixed orifice tube influences the refrigerant pressure in both heat exchangers as well as the refrigerant mass distribution during the stop-start transients. Therefore, an accurate valve model is necessary. Equation (6) is used to calculate the orifice mass flow rate, where the flow coefficient $C_{f}$ is determined via a semi-empirical mapping approach [8], and the refrigerant density $\rho_{v}$ is assumed to be a function of the refrigerant inlet conditions (i.e., liquid-vapor mixture, or vapor) to the orifice tube, as given in (7).

$$
\begin{gathered}
\dot{m}_{v}=C_{f} \sqrt{\rho_{v}\left(P_{l t}-P_{e}\right)} \\
\rho_{v}=\rho\left(P_{l t}, h_{i, v}\right)
\end{gathered}
$$

The compressor model illustrated in [ 5$]$ has been demonstrated to predict the refrigerant mass flow after system start-up with sufficient accuracy to be useful for simulation purposes. The compressor mass flow rate is computed by:

$$
\dot{m}_{k}=V_{k} \omega_{k} \rho_{k} \eta_{v o l}
$$

where $V_{k}$ is the cylinder volume, $\omega_{k}$ is the compressor speed, and $\rho_{k}$ is the refrigerant inlet density. The volumetric efficiency $\eta_{v o l}$ is found using a performance mapping approach similar to the one given in []]

\section{REFRIGERANT MASS CALCULATION}

Approaches are explored here to evaluate the refrigerant mass distribution behaviors in the stop-start operation. Poggi et al. [9] presents a summary of available refrigerant mass calculation methods in the literature. The authors in [9] also 
point out that the major challenge is the mass evaluation in two-phase components, such as heat exchangers. For general numerical simulations, the refrigerant mass migration in each system component can be obtained by Equation (9) with known refrigerant inlet and outlet mass flow rate conditions. An alternative way to evaluate the refrigerant mass distribution in heat exchangers during transients is using the mean void fraction $\bar{\gamma}_{c}$ and $\bar{\gamma}_{e}$, which is an integral form of a local void fraction. The Zivi local void fraction correlation [10] is applied in this study. The two-phase and single-phase (vapor or liquid) refrigerant mass calculations in the heat exchangers are given in Equations (10) and (11).

$$
M_{\text {componont }}=M_{\text {steaty }- \text { state }}+\int\left(\dot{m}_{i}-\dot{m}_{o}\right) d t
$$

$$
M_{\text {mo-phase.ecchengers }}=\left(\bar{\gamma} \rho_{g}+(1-\bar{\gamma}) \rho_{f}\right) \zeta_{\text {nvo-phase }} V_{\text {exchangers }}
$$

$$
M_{\text {single-phase,exchangers }}=\rho_{\text {single }- \text { phase }} \zeta_{\text {single-phase }} V_{\text {exchangers }}
$$

The total refrigerant mass in the automotive air conditioning system (see Figure 1) is described below.

$M_{\text {toud }}=M_{\text {exchungers }}+M_{\text {accumulator }}+M_{\text {liquid_tube }}+M_{\text {compressor }}+M_{\text {pipes }}$

where the calculation of the single-phase refrigerant mass in components, such as superheated vapor in pipes, is based on the refrigerant density and component volume information.

\section{SIMULATION ENVIRONMENT}

To validate the refrigerant mass migration during the compressor stop-start operations, the component models described above, along with pipe models connecting each component, are implemented in Thermosys [8], a Matlab/ Simulink toolbox for simulation. The pipe models calculate pressure drops between any two components. The inputs to each model are generally the outputs of other component models. For instance, the refrigerant inlet and outlet mass flow rates are the evaporator model inputs, yet they themselves are the outputs of the fixed orifice tube and compressor model, respectively. Numerical solution procedures on the switched heat exchanger models are given in [7]. Detailed information about the air-side and refrigerantside heat transfer calculations in transients can be found in [5].

\section{MODEL VALIDATION}

As mentioned earlier, the refrigerant mass migration experimental data presented in [4] are used for transient validation in the paper. The model validation study, consists of three stop-start step changes in compressor speed (see Figure 4) while maintaining the air flow rates across the heat exchangers. The steps in the system inputs for the validation are summarized in Table 1 along with the condenser and evaporator air inlet temperature conditions. The first compressor stop-start operations are identical to the experimental scenario studied in [4]. The three compressor shut-down time periods are 3 minutes, 2 minutes and 1 minute respectively.

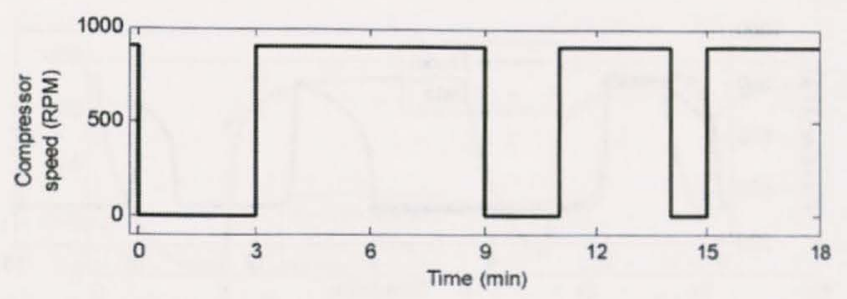

Figure 4. Compressor speed input for validation.

Table 1. System operating conditions for validation.

\begin{tabular}{|c|c|c|c|}
\hline Input & $\begin{array}{c}\text { Step time for } \\
\text { shut-down }\end{array}$ & $\begin{array}{c}\text { Before } \\
\text { shut-down }\end{array}$ & $\begin{array}{c}\text { Step time } \\
\text { for start-up }\end{array}$ \\
\hline $\begin{array}{c}\text { Compressor } \\
\text { speed }\end{array}$ & $\begin{array}{c}130 \mathrm{~s} / 670 \mathrm{~s} \\
/ 970 \mathrm{~s}\end{array}$ & $900 \mathrm{rpm}$ & $\begin{array}{c}310 \mathrm{~s} / 790 \mathrm{~s} \\
/ 1030 \mathrm{~s}\end{array}$ \\
\hline $\begin{array}{c}\text { Cond. air } \\
\text { mass flow rate }\end{array}$ & $0.525 \mathrm{~kg} / \mathrm{s}$ \\
\hline $\begin{array}{c}\text { Evap. air mass } \\
\text { flow rate }\end{array}$ & $0.156 \mathrm{~kg} / \mathrm{s}$ \\
\hline $\begin{array}{c}\text { Cond. air inlet } \\
\text { temperature }\end{array}$ & $35^{\circ} \mathrm{C}$ \\
\hline $\begin{array}{c}\text { Evap. air inlet } \\
\text { temperature }\end{array}$ & $35^{\circ} \mathrm{C}$ \\
\hline
\end{tabular}

The plots in Figures $5, \underline{6}, \underline{7}, \underline{8}, \underline{9}$ compare the experimental results with the system model outputs and demonstrate good agreement. During the compressor shut-down period, the refrigerant migrates from the high-pressure to the lowpressure components through the fixed orifice tube, which results in the heat exchanger pressure changes as seen in Figures 5 and $\underline{6}$. The evaporator air outlet temperature, as shown in Figure 7 , increases towards the ambient temperature $\left(35^{\circ} \mathrm{C}\right)$ as the thermal mass of the heat exchanger and refrigerant mass inside approach an equilibrium condition. In addition, the system model predicts the transients of the refrigerant mass flow rate across the compressor at start-up shown in Figure 9. 


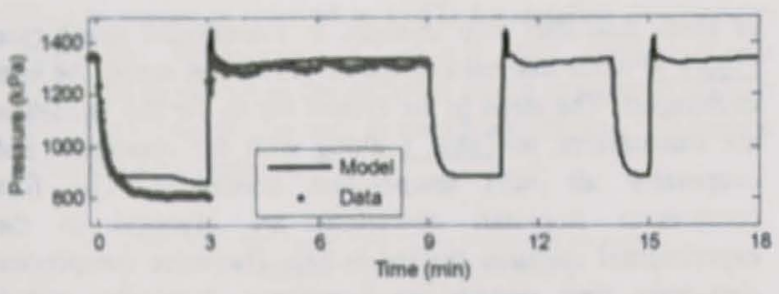

Figure 5. Condenser pressure.

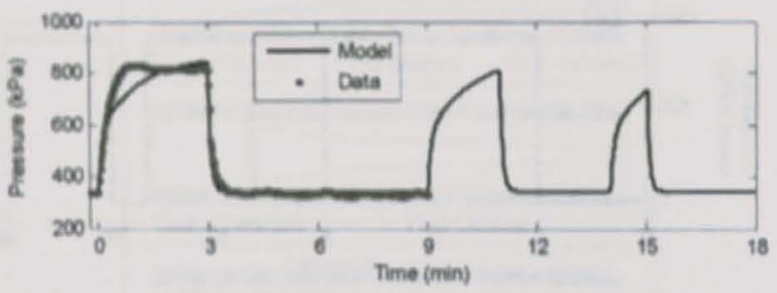

Figure 6. Evaporator pressure.

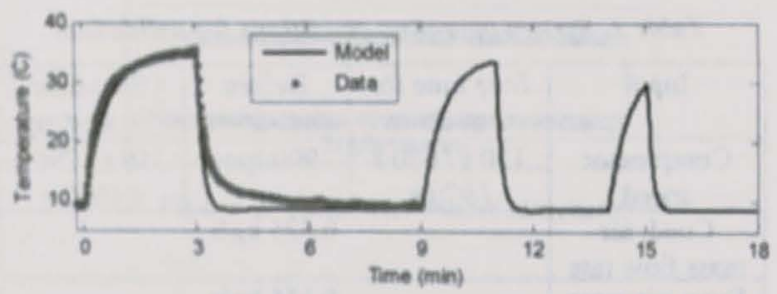

Figure 7. Evaporator air outlet temperature.

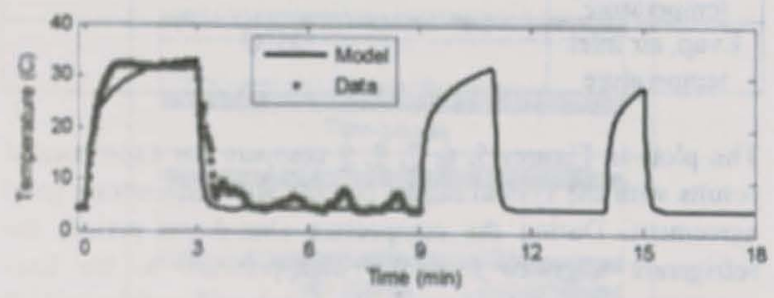

Figure \&. Evaporator refrigerant outlet temperature.

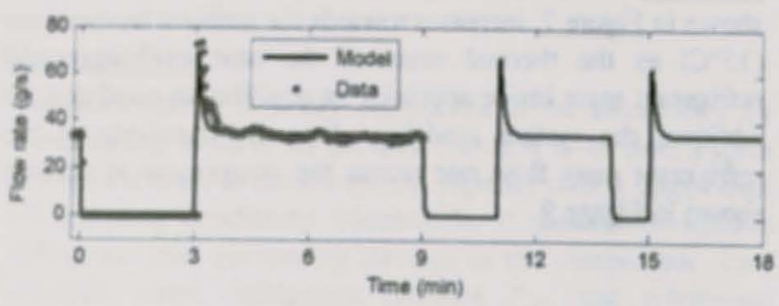

Figure 9. Refrigerant mass flow rate across the compressor.

The comparison of the total refrigerant mass in the experimental system and the system model is given in Eigure
10. The total refrigerant mass in the experimental system differs up to $2.7 \%$ from the target refrigerant mass of $1000 \mathrm{~g}$ as a result of the measurement technique used. The amount of refrigerant mass is constant in the transient simulation, which proves the validity of the switched modeling approach discussed above. Compared to the total refrigerant mass in the experimental study, the $10 \%$ deviation of the total refrigerant mass in the system model prediction is a result of the refrigerant mass in the compressor crankcase which the current compressor model does not account for.

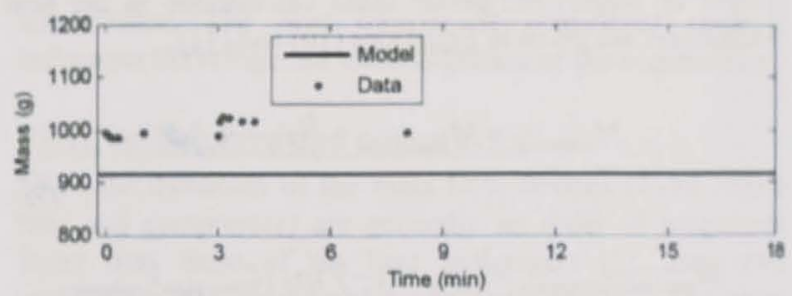

Figure 10. Total refrigerant mass in the system.

The refrigerant mass migration during the transient scenario is shown in Figures 11 and 12. The experimental results show that before the system turns off, $58 \%$ of the total refrigerant mass is located in the high-pressure components (condenser and liquid tube). Three minutes after the compressor is stopped, only $11 \%$ of the total refrigerant mass is found in these components. The root mean square (RMS) value is used to quantify the model mass prediction performance. Approximately $8 \%$ error is found in predieting the refrigerant mass migration in the high-pressure components, and the prediction error is $4 \%$ for the migration in the low-pressure components as shown in Figure 12.

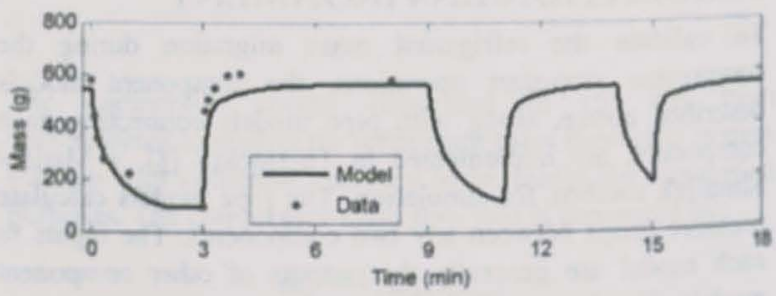

Figure II. Refrigerant mass migration in the highpressure components. 


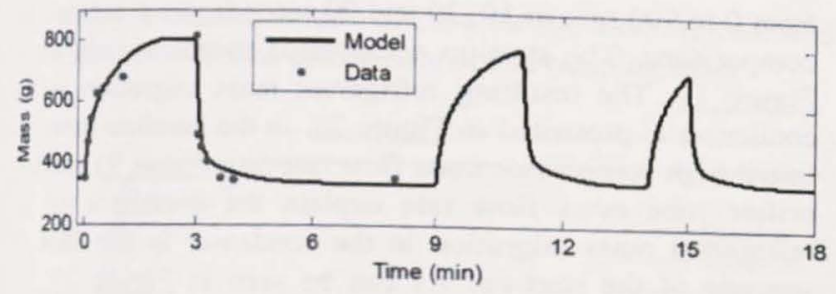

Figure 12. Refrigerant mass migration in the lowpressure components.

Figure 13 describes the dynamic switching of different model representations in the condenser model structure (see Figure 2) for this validation scenario, where relevant switching criteria are discussed in [5]. The condenser model switches from the initial three-zone (superheated, two-phase and subcooled) model to the final one-zone (superheated) model during the compressor shut-down period. The vapor and liquid refrigerant transients are tracked through the model switching techniques, which enables the calculation of refrigerant mass variations using Equations (10) and (11). The refrigerant mass migration in the condenser component is given in Figure 14, while Figure 15 presents the refrigerant migration inside the liquid tube component. However, it should be noted here that the reversion of refrigerant flow from the liquid tube to the condenser component during the first 5 seconds of the shut-down period, which leads to a temporary increase of the refrigerant mass inside the condenser as reported in [4], is not captured by the system model.

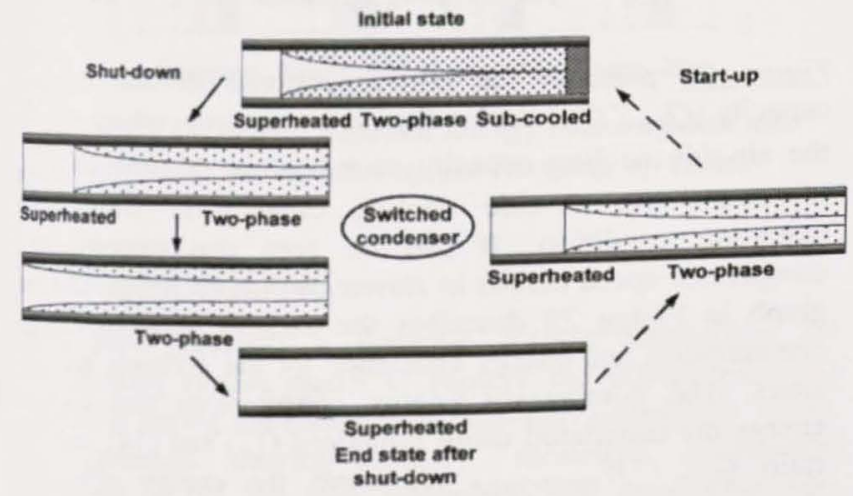

Figure 13. Switching schemes in the condenser.

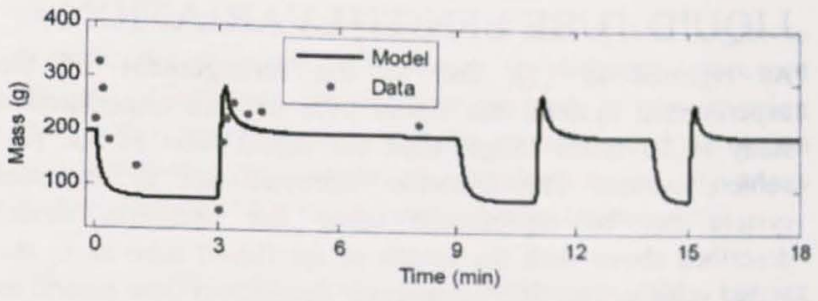

Figure 14. Refrigerant mass migration in the condenser.

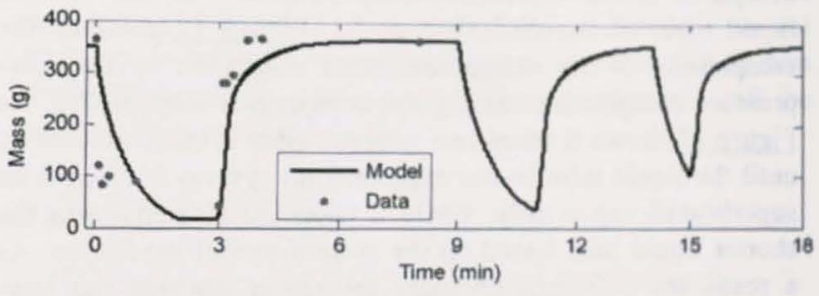

Figure 15. Refrigerant mass migration in the liquid tube.

As shown in Figure 12, prior to system start-up, over $80 \%$ of the total refrigerant mass is located in the low-pressure components (evaporator and accumulator), $56 \%$ of the total refrigerant mass is in the accumulator. Figure 16 presents the refrigerant mass migration in the accumulator. During the first 60 seconds of the compressor stop period, the pressure gradient across the fixed orifice tube drives the refrigerant mass into the evaporator and the accumulator. After 60 seconds, the refrigerant mass migration to the accumulator continues as a result of the temperature gradient, and the accumulator has the lowest temperature in the system during this time frame. All the validation results demonstrate the capability of the developed automotive system model in predicting the refrigerant mass migration during repetitive stop-start operations of the compressor.

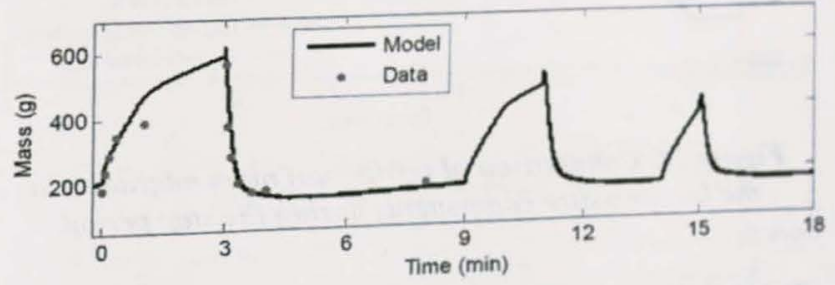

Figure 16. Refrigerant mass migration in the accumulator.

\section{SIMULATION EXAMPLES}

To further investigate the potential of the dynamic modeling approach presented, two simulation examples are given in this section to evaluate the system performance within different system configurations and control strategies. 


\section{LIQUID TUBE LENGTH VARIATION}

As reported in [4], due to the arrangement of the experimental system, the liquid tube for the experimental study is 3.7 times longer than the liquid tube of the real vehicle system. The dynamic characteristics of the real system can be represented using the dynamic model described above with the length of the liquid tube as in the actual vehicle. The first compressor shut-down time period as seen in Figure 4 is applied here. The refrigerant mass migration in the liquid tube in the experimental system is compared to the system model prediction with the shorter liquid tube, as shown in Eigure 17. Figure 18 presents the comparison of the refrigerant mass migration in the lowpressure components during the compressor stop period. As Figure 17 shows it takes two minutes after system shut-down until the liquid tube in the experimental system is filled with superheated vapor only, while it takes 20 seconds with the shorter liquid tube based on the system model prediction. As a result the refrigeration mass migration towards the lowpressure components is achieved earlier for the shorter liquid tube.

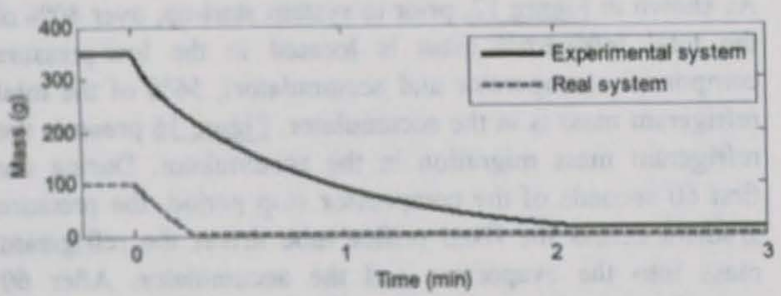

Figure 17. Comparison of refrigerant mass migration in the liquid tube during the stop period.

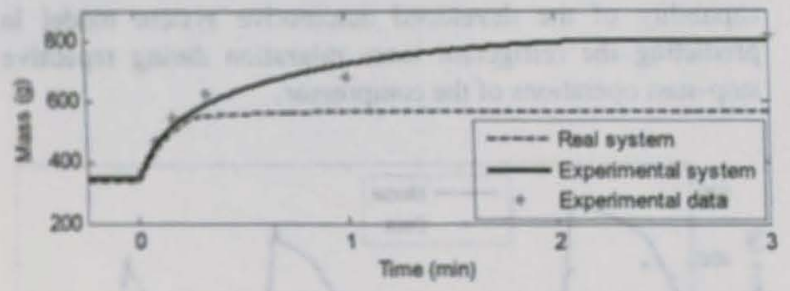

Flgure 18. Comparison of refrigerant mass migration in the low-pressure components during the stop period.

\section{RAMPING COMPRESSOR SPEED AT START-UP}

The modeling and simulation tools presented enable the implementation of control strategies to improve the automotive system performance. In this simulation example, the performance variations are investigated if the compressor is speed is increased linearly during the start-up. The baseline case has a step change of the compressor speed as shown in Figure 4 . Three other cases, ramping the compressor speed from 0 to $900 \mathrm{rpm}$ in 10,30 and 90 seconds, are presented for comparisons. The start-up compressor speeds are shown in Figure 19. The resulting refrigerant mass migration in the condenser is presented in Figure 20. In the baseline case, the initial high compressor mass flow rate (see Figure 9) and low orifice tube mass flow rate explain the overshoot of the refrigerant mass migration in the condenser in the first 20 seconds of the start-up. As can be seen in Figure 20, the overshoot phenomenon becomes less obvious with an increase in compressor speed ramping time.

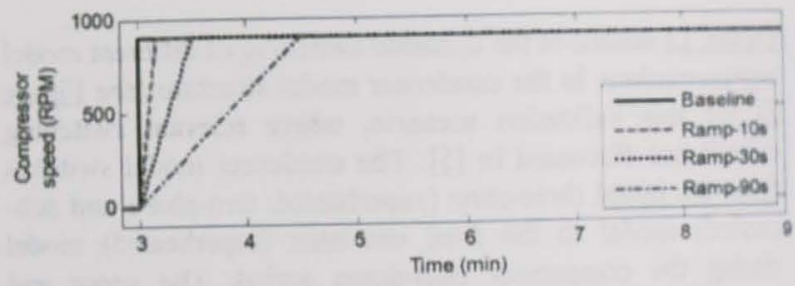

Figure 19. Compressor speed input for ramping up cases.

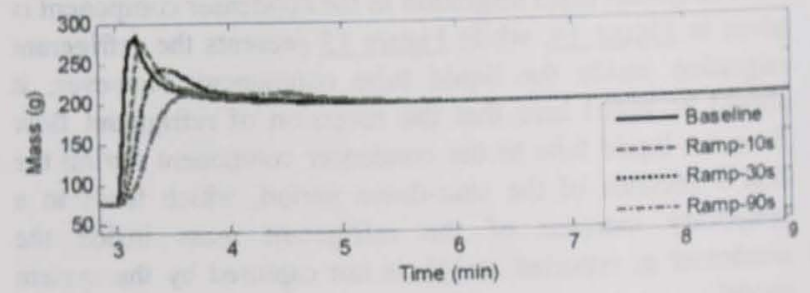

Figure 20. Refrigerant mass migration in the condenser for ramping up cases.

Figure 21 presents the non-dimensional air-side cooling capacity $\left(Q_{a i r} / Q_{s s}\right)$ during the system start-up, where $Q_{a r}$ is the air-side cooling capacity as a function of time and $Q_{s s}$ represents the air-side cooling capacity at steady-state operating condition. It can be seen that ramping the compressor speed results in slower cool-down times. The bar graph in Figure 22 describes the tradeoff between energy consumption and energy efficiency for the different start-up cases. The compressor energy consumption and cooling energy are calculated using Equations (13) and (14), and the ratio $Q_{\text {air }} / W_{\text {compressor }}$ represents the energy efficiency during the system start-up. The integration time applied here is the first 100 seconds of the start-up. As shown in Figurc 22. an increase in ramping time results in a more energy efficient start-up performance (the ratio increases from 2.08 in the baseline case to 2.25 in the ramp-30s case and 2.78 in the ramp-90s case), at the expense of the cooling energy reduction provided to the passenger compartment (the cooling energy drops from $285.47 \mathrm{~kJ}$ in the baseline case to $246 \mathrm{~kJ}$ in the ramp-30s case and $177.65 \mathrm{~kJ}$ in the ramp-90s case). The model prediction results here are in good agreement with the experimental ramping study presented in 
[6] which determines a ratio of 2.04 for the baseline case and 2.33 for the 30 second compressor speed ramping case.

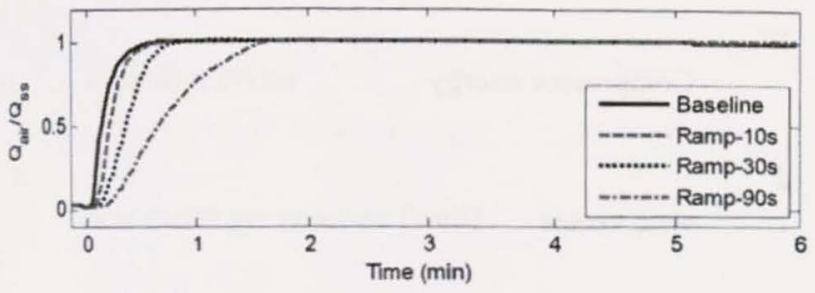

Figure 21. Air-side cooling capacity during start-up for ramping up cases.

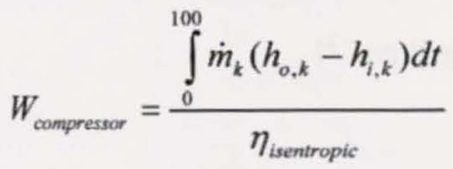

$$
Q_{\text {air }}=\int_{0}^{100} \dot{Q}_{\text {air }} d t=\int_{0}^{100} \dot{m}_{\text {air }, e} c_{\text {air }}\left(T_{i, \text { air }, e}-T_{o, \text { air }, e}\right) d t
$$

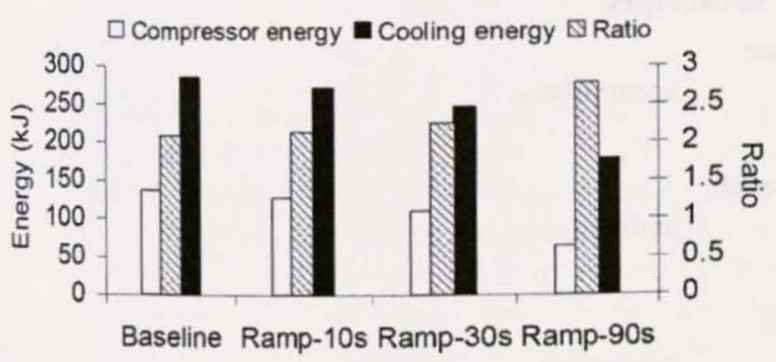

Figure 22. Tradeoff between energy consumption and efficiency during start-up for ramping up cases.

\section{CONCLUSIONS}

This paper presents a dynamic R134a automotive air conditioning system model to capture the refrigerant mass migration during the compressor stop-start operations. Using the switched moving-boundary modeling framework presented in [5], the heat exchangers are developed with switched model representations to accommodate the refrigerant phase changes in transients. The validation against experimental data from [4] shows that the system model is able to well predict the refrigerant mass migration among the system components during the shut-down period and the refrigerant redistribution after system start-up, with the mass prediction error between $4 \%$ and $8 \%$. The results also demonstrate the capability of the developed automotive system model in predicting the refrigerant mass migration during repetitive stop-start operations of the compressor. The presented simulation example with the variations of the liquid tube length shows the potential of the system model to evaluate the transient performance for different component designs. Moreover, it is demonstrated in the ramping compressor speed scenario that the modeling and simulation tools presented here enable the implementation of various control strategies for system performance improvement.

Future work will involve investigations for varying temperature conditions and the effect on system start-up performance, such as refrigerant mass migration among system components during long system stop periods to represent a vehicle parked overnight. Advanced control strategies to improve the automotive air conditioning system performance upon varying operation conditions will be another focus of future work.

\section{REFERENCES}

1. Rubas, P.J., Bullard, C.W., "Factors Contributing to Refrigerator Cycling Losses," International Journal of Refrigeration 18(3): 168-176, 1995.

2. Wang, J., Wu, Y., "Start-up and Shut-down Operation in a Reciprocating Compressor Refrigeration System with Capillary Tubes," International Journal of Refrigeration 13(3): 187-190, 1990.

3. Peuker, S., Hrnjak, P.S., "Refrigerant Mass and Oil Migration during Start-up Transient," presented at the $12^{\text {nd }}$ International Refrigeration and Air Conditioning Conference at Purdue, USA, July 14-17, 2008.

4. Peuker, S. and Hrnjak, P.S., "Transient Refrigerant Migration and Oil Distribution of an R134a Automotive A/C System," SAE Int. J. Passeng. Cars - Mech. Syst. 2(1): 714-724, 2009, doi:10.4271/2009-01-0534.

5. Li, B., Alleyne, A.G., "A Dynamic Model of a Vapor Compression Cycle with Shut-down and Start-up Operations," International Journal of Refrigeration 33(3): 538-552, 2010.

6. Peuker, S., "Experimental and Analytical Investigation of Refrigerant and Lubricant Migration," Ph.D. thesis, Department of Mechanical Science and Engineering, University of Illinois at Urbana-Champaign, USA, 2010.

7. McKinley, T.L., Alleyne, A.G., "An Advanced Nonlinear Switched Heat Exchanger Model for Vapor Compression Cycles using the Moving-boundary Method," International Journal of Refrigeration 31(7): 1253-1264, 2008.

8. Rasmussen, B.P., "Dynamic Modeling and Advanced Control of Air Conditioning and Refrigeration Systems," Ph.D. thesis, Department of Mechanical Science and Engineering, University of Illinois at Urbana-Champaign, USA, 2005.

9. Poggi, F., Macchi-Tejeda, H., Leducq, D., Bontemps, A., "Refrigerant Charge in Refrigerating Systems and Strategies 